\title{
The Prospect and Feasibility Assessment of Brine Shrimp (Artemia franciscana) Culture in Bangladesh
}

\author{
M Niamul Naser, Rajib Hasan, Sharmin Akter Nipa and Harun Or Rashid \\ Department of Zoology, University of Dhaka, Dhaka 1000, Bangladesh
}

\begin{abstract}
A laboratory-based work was conducted on development, biometry (cyst diameter, hatching efficiency and hatching percentage) and survival rate of Artemia franciscana at 35 ppt using natural brine water under constant aeration facilities. The experiment was carried out for both chorionic and decapsulated cysts. There was a significant increase in hatching output of the decapsulated cysts than the chorionic cysts. The survival rate was counted only for the chorionic cysts because nauplii hatched from decapsulated cysts died after four days of incubation before reaching the adult stage. Untill now the Artemia cysts are imported from abroad. Though the prospect of mass production of Artemia in Bangladesh is feasible but there needs to be more studies done.
\end{abstract}

Key words: Cyst diameter, hatching output, decapsulation, survival rate.

\section{Introduction}

Artemia, also known as brine shrimp, is a minute crustacean, has become an easy and most convenient food items among the live diets used in aquaculture of fishes. Over the course of time it has gained much popularity in many aquaculturists because of its multiple usages in fish culture with various forms such as Artemia nauplii, decapsulated Artemia cysts and on-grown Artemia [1]. Likewise the rearing of such highly nutritious feed item is quite easy.

In most intensive aquaculture system, the newborn fish larvae rely on live food items. But the culture and collection of highly nutritious natural food such as crustaceans for rearing the fish are not only always economically feasible but also poorly available. Crustaceans occur naturally on hypersaline water which acts as the predominant factor for prohibiting Artemia populations from being present in humid climatic conditions like Bangladesh [2].

Artemia is being used in large scale in the hatcheries of Bangladesh since it is one of the key items in shrimp and fishery hatcheries. However,

Corresponding author: Rajib Hasan, research assistant, research field: conservation biology and zoology (fisheries science). because of its unusual occurrence and the difficulties of collecting cysts, Artemia cysts are being commercially imported from abroad countries to meet up the increasing demand where the mass production of cysts of Artemia in Bangladesh is still at the premature stage. Although a number of fundamental works have been conducted on Artemia under laboratory condition, only a few preliminary works on mass Artemia production have been reported. Some major studies were conducted on the production of Artemia biomass and cysts from the traditional solar salt beds of coastal areas of Bangladesh [3-5]. Results revealed that the modified solar salt beds of Bangladesh have suitable water quality that can be used for salt Artemia production in winter season. So the present 12,000 ha of salt farming area of Bangladesh can be used to produce 180 metric tons of dry cysts and 2,400 metric tons of biomass per annum [6]. In Thailand, Artemia is produced in modified salt pans integrated with shrimp production. So there is a potential prospect in our country to get mass Artemia production by using 275,583 ha shrimp farming area if proper initiatives are taken carefully.

In this present study the development, hatching and survival of Artemia franciscana were closely examined 
on the laboratory reared animals. Besides these observations, water quality parameters such as water temperature, salinity and $\mathrm{pH}$ were measured carefully.

\section{Materials and Methods}

\subsection{Hatching of Artemia Cysts}

Simple aquarium tanks were used for hatching of nauplii from Artemia cysts. Unpurified brine water was used as culture media. Salinity level was adjusted by using tap water. The culture media was then oxygenated by an aerator pump, and placed it in front of a fluorescent light (60 watt) until the study period ended. Continuous aeration was provided to keep the cysts in suspension and to provide enough oxygenation. Since Artemia is a specific filter feeder, the nauplii were fed with natural phytoplankton known as Spirulina.

\subsection{Decapsulation}

For decapsulation, 0.1 gram of dry cysts were taken in a conical, transparent plastic container and incubated in salt water for 1 to 2 hours to ensure the complete hydration. After 2 hours, 0.5 gram of bleaching powder was added to the salt water and the media was aerated. Ice was added to the media to maintain the temperature not beyond of $40{ }^{\circ} \mathrm{C}$. The color of the cysts was observed carefully. When the color of the cysts changed from dark brown to orange, the cysts were filtered from the decapsulation solution and rinsed with cool tap water until no chlorine smell persisted. The sample of decapsulated cysts were then incubated for determining hatching efficiency and hatching percentage [7].

\subsection{Hatching Efficiency and Hatching Percentage}

$80 \mathrm{~mL}$ of salt water was taken in $250 \mathrm{~mL}$ measuring conical flask. The media was then aerated and $250 \mathrm{mg}$ cysts were added. After one hour, the $100 \mathrm{~mL}$ volume was made by adding salt water. Continuous aeration and light illumination were provided. After 24 hours and 48 hours of incubation, 5 subsamples containing
$0.25 \mathrm{~mL}$ were taken from the conical flask. Then the number of nauplii and unhatched cysts were counted. The two parameters were determined using Eqs. (1) and (2) (Sorgeloos and Kulasekarapandian 1984):

Hatching efficiency $=$ Number of nauplii per gram of cysts (1)

Hatching percentage (\%) = Number of nauplii $\times 100 /$ number of nauplii+number of unhatched cysts (2)

\subsection{Diameter of Cysts}

The diameter of both chorionic and decapsulated cysts were measured under microscope (at $10 \mathrm{X}$ magnification) using an ocular micrometer. The cysts were collected after 2 hours of incubation. From the mean diameter, chorionic thicknesses were measured using Eq. (3) [8]:

Chorionic thickness $=$ Mean diameter of chorionic cysts-mean diameter of decapsulated cysts/2 (3)

\subsection{Water Quality Parameters}

Water quality parameters such as $\mathrm{pH}$, salinity and water temperature were observed during the experiment at different day intervals.

\subsection{Survival Rate}

Survival rate was determined at water renewal on days 8th, 12th, 15th, 20th and 23th. The rate was determined on the basis of the number of developing larvae survived on the representative days.

\section{Results}

\subsection{Development}

After hydration the biconcave cysts became spherical and the embryos became visible under microscope after 9 hours to 10 hours of incubation when they started to protrude through the fissure. Prior to hatching, the embryos are found to be hanging from the cyst shells (Fig. 1). The embryo, following the hatching, developed into an oval shape having a single naupliar eye and covered by a thin membrane through 
which it was attached to the cyst shell (Fig. 2).

Within a short period of time the free-swimming first naupliar (instar I) stage (Fig. 3) came out through the rupture of the embryonic membrane. It was the non-feeding stage with a mean body length of $0.502 \pm$ $0.0156 \mathrm{~mm}$. The nauplii were brownish orange in color because of their yolk reserves. A few hours after the hatching of first instar, it developed into the second larval stage (instar II) having a mean length of $0.614 \pm 0.0183 \mathrm{~mm}$. The instar I could be differentiated from the instar II by the quick lashing movements of the instar II larvae. The third larval stage was observed on the third day of incubation with a mean length of $0.822 \pm 0.0115 \mathrm{~mm}$. This larval stage was persisted for the next few hours and then molted into the fourth larval stage having a body length of $0.90 \pm 0.094 \mathrm{~mm}$.

During the next few days, the nauplii had undergone several molting and reached into the adult stage. The adults were observed from the 20th day after incubation with a mean body length of $8.46 \pm$ $0.074 \mathrm{~mm}$ (Fig. 4).

The larval stages with their days of observation and body lengths are summarized in Table 1.

\subsection{Physico-Chemical Parameters}

Physico-chemical parameters like water temperature, $\mathrm{pH}$ and salinity were recorded on different days of observation. There was a gradual increase of salinity from 35 ppt to 54 ppt onwards with the culture system.

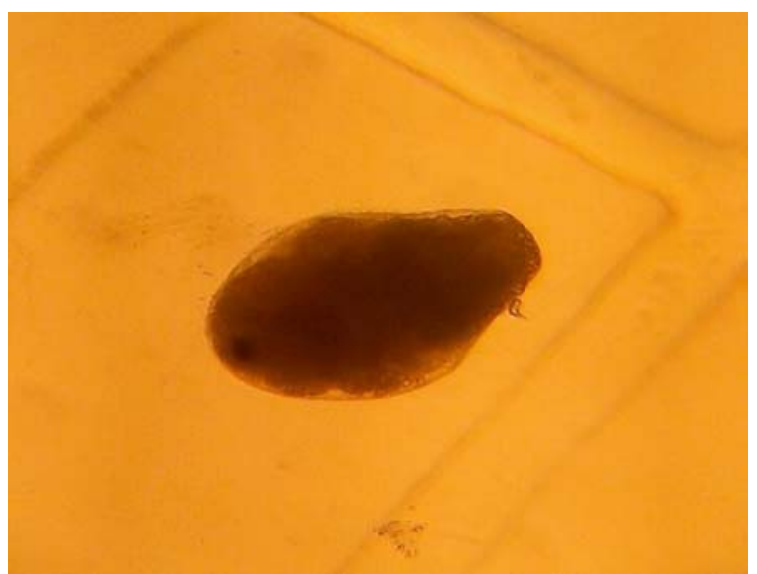

Fig. 1 Embryo on hatching.

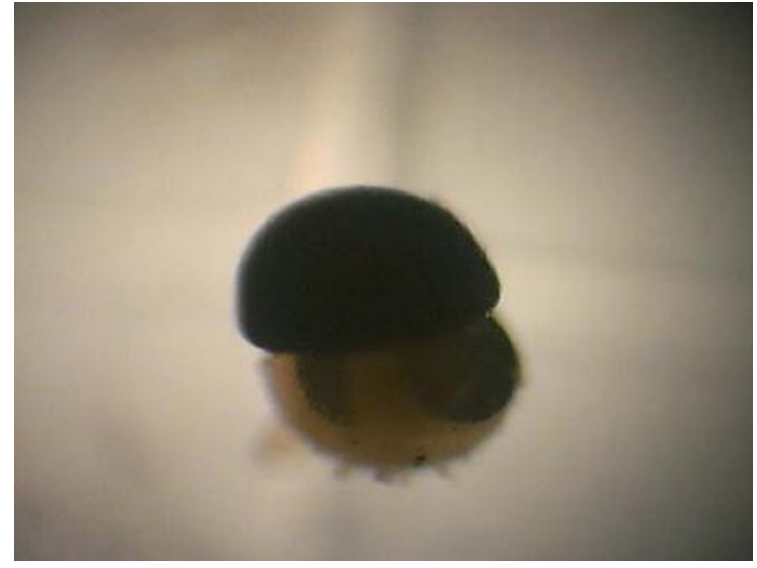

Fig. 2 Oval-shaped pre-nauplius.

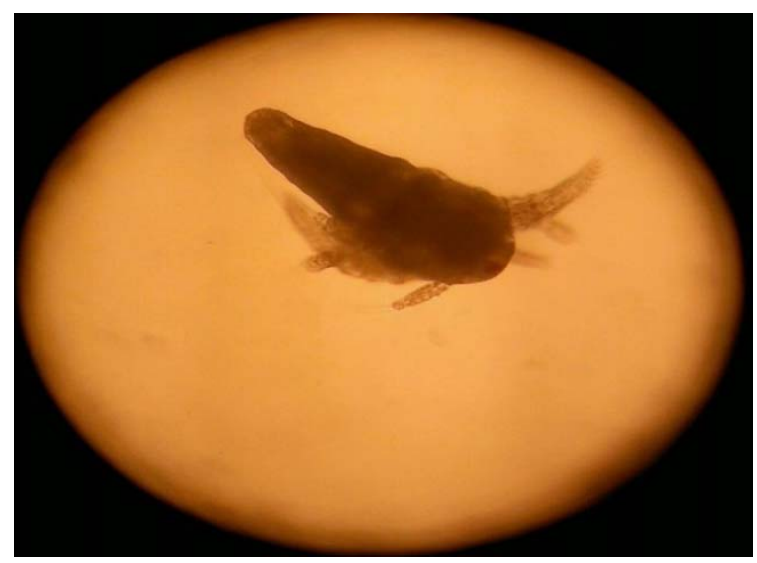

Fig. 3 1st naupliar stage (instar I).

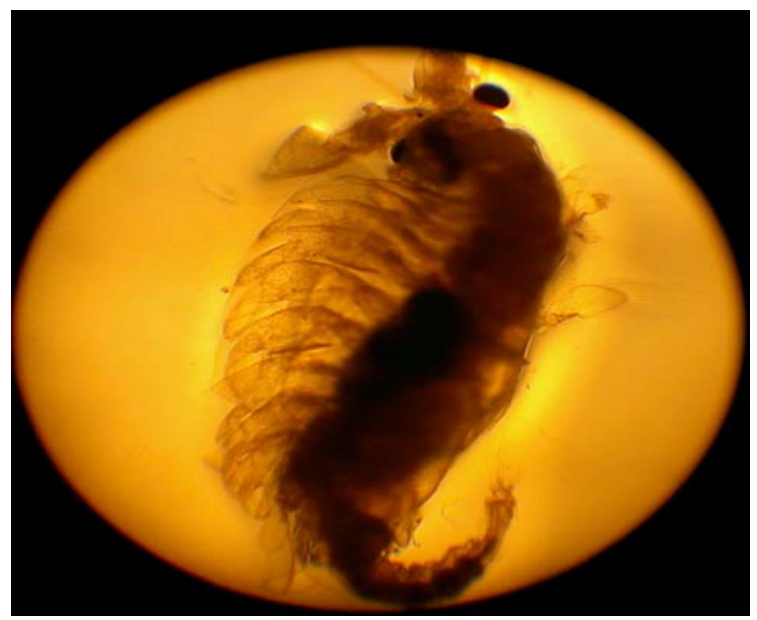

Fig. 4 Adult (male).

No significant variation was observed in case of $\mathrm{pH}$ and remained within a range of 7.4 to 7.7. The temperature showed a little fluctuation, the lowest temperature recorded was $26.4^{\circ} \mathrm{C}$ and the highest was $31.5^{\circ} \mathrm{C}$ (Table 2). 
Table 1 Body length of larval stages.

\begin{tabular}{llllll}
\hline $\begin{array}{l}\text { Name of larval } \\
\text { stages }\end{array}$ & $\begin{array}{l}\text { Specific days of } \\
\text { observation }\end{array}$ & $\begin{array}{l}\text { Body length }(\mathrm{mm}) \\
(\text { Mean } \pm \text { SE) }\end{array}$ & $\begin{array}{l}\text { Name of larval } \\
\text { stages }\end{array}$ & $\begin{array}{l}\text { Specific days of } \\
\text { observation }\end{array}$ & $\begin{array}{l}\text { Body length (mm) } \\
\text { (Mean } \pm \text { SE) }\end{array}$ \\
\hline 1st Larval stage & 20 hours & $0.502 \pm 0.0156$ & 6th Larval stage & 8th & $1.46 \pm 0.024$ \\
2nd Larval stage & 2nd day & $0.614 \pm 0.0183$ & 7th Larval stage & 9th & $1.95 \pm 0.074$ \\
3rd Larval stage & 3rd day & $0.822 \pm 0.0115$ & 8th Larval stage & 13th & $2.84 \pm 0.143$ \\
4th Larval stage & 6th day & $0.90 \pm 0.094$ & Juvenile & 16th & $5.32 \pm 0.259$ \\
5th Larval stage & 7th day & $0.992 \pm 0.0048$ & Adult & 20th & $8.46 \pm 0.074$ \\
\hline
\end{tabular}

Table 2 The physico-chemical parameter of water during the different days of observation.

\begin{tabular}{|c|c|c|c|c|c|c|c|c|c|c|c|c|c|}
\hline \multirow{2}{*}{ Water parameters } & \multicolumn{13}{|c|}{ Specific days of observation } \\
\hline & 1 th & 2th & 3th & 6th & 8th & 9th & 10th & 12th & 15th & 17th & 18th & 20th & 23th \\
\hline Salinity & 35 & 35 & 35 & 36 & 38 & 40 & 41 & 43 & 46 & 48 & 51 & 53 & 54 \\
\hline $\mathrm{pH}$ & 7.4 & 7.4 & 7.4 & 7.5 & 7.5 & 7.6 & 7.5 & 7.5 & 7.6 & 7.7 & 7.6 & 7.4 & 7.4 \\
\hline Temperature $\left({ }^{\circ} \mathrm{C}\right)$ & 26.4 & 26.5 & 26.5 & 26.6 & 26.4 & 27.1 & 26.8 & 27.8 & 29.5 & 31.5 & 26.8 & 26.6 & 26.5 \\
\hline
\end{tabular}

Table 3 Determination of chorionic thickness.

\begin{tabular}{|c|c|c|c|c|}
\hline \multicolumn{2}{|c|}{$\begin{array}{l}\text { Diameter of chorionic cysts }(\mu \mathrm{m}) \\
(\text { Mean } \pm \mathrm{SE})\end{array}$} & $\begin{array}{l}\text { Diameter of untreated cysts }(\mu \mathrm{m}) \\
(\text { Mean } \pm \mathrm{SE})\end{array}$ & \multicolumn{2}{|c|}{ Chorionic thickness } \\
\hline \multicolumn{2}{|l|}{$242.2 \pm 1.90$} & $213.5 \pm 3.167$ & \multicolumn{2}{|c|}{14.35} \\
\hline \multirow{2}{*}{ Cyst type } & \multicolumn{2}{|c|}{ Hatching efficiency (N/gm cysts) } & \multicolumn{2}{|c|}{ Hatching percentage (\%) } \\
\hline & 24 hours & 48 hours & 24 hours & 48 hours \\
\hline Untreated cysts & $5.6 \times 10^{4}$ & $8.96 \times 10^{4}$ & $36 \%$ & $48 \%$ \\
\hline Decapsulated cysts & $1.02 \times 10^{5}$ & $1.42 \times 10^{5}$ & $56 \%$ & $90 \%$ \\
\hline
\end{tabular}

Table 5 Survival percentage of Artemia franciscana.

\begin{tabular}{llllll}
\hline & \multicolumn{5}{l}{ Specific days of observation } \\
\cline { 2 - 6 } & 8th & 12th & 15th & 20th & 23th \\
\hline No. of nauplii & 133 & 107 & 100 & 97 & 92 \\
Survival percentage (\%) & $100 \%$ & $80.45 \%$ & $75.18 \%$ & $72.93 \%$ & $69.17 \%$ \\
\hline
\end{tabular}

\subsection{Cyst Diameter}

The mean values for chorionic and decapsulated cysts were $242.2 \pm 1.90 \mu \mathrm{m}$ and $213.5 \pm 3.167 \mu \mathrm{m}$ respectively. The chorionic thickness was measured from the mean diameter of chorionic hydrated and decapsulated cysts and the value is $14.35 \mu \mathrm{m}$ (Table 3).

\subsection{Hatching Efficiency and Hatching Percentage}

The results of hatching efficiency and hatching percentages are presented in Table 4. Where, the differences are noticeable in both hatching efficiency and hatching percentages. The hatching efficiency and the hatching percentages of decapsulated cysts were higher than that of chorionic cysts.

\subsection{Survival Percentage}

During the experiment, the survival rate of Artemia nauplii was also determined at water renewal on days 8th, 12th, 15th, 20th and 23th to study the effect of salinity on survival of Artemia. The number of the developing embryo was 133 on the 8th day of the experiment. There was a gradual decrease of the number of larvae onwards with the culture periods. On the 23th day, about 92 growing larvae were observed 
and the survival percentage was $69.17 \%$.

\section{Discussion}

The growth, survival, metabolism and number of instars of Artemia are critically dependent on environmental factors. This extremely euryhaline animal grows well when the salinity, temperature and $\mathrm{pH}$ are favorable. The effects of these water quality parameters on the survival, reproduction and morphology have been studied by many authors. A study found that the survival temperature of Artemia is ranging from $15{ }^{\circ} \mathrm{C}$ to $55{ }^{\circ} \mathrm{C}$ [9]. Cyst hatching output is greatly compromised at $\mathrm{pH}$ below 5 [10]. The effect of $\mathrm{pH}$ on the hatching percentage, survival and reproduction of Artemia strains was studied [11]. Artemia can withstand salinity 3 ppt to 300 ppt [9]. Under laboratory condition, development of Artemia at salinity 35 ppt showed a good result in the experiment [12]. In the present study, the culture was done at a salinity of $35 \mathrm{ppt}$, showed a good result in survival, development and hatching output of Artemia franciscana. Temperature $\left(26.4{ }^{\circ} \mathrm{C}\right.$ to $\left.31.5^{\circ} \mathrm{C}\right)$ and $\mathrm{pH}$ (7.4 to 7.7 ) were also optimum during the study period.

In the present study, Artemia reached the adult stage on the 20th day and the adults were $8.46 \pm 0.07$ $\mathrm{mm}$ in length. When Artemia was cultured in salt ponds it reached adult stage in 16th to 19th days [13]. Artemia reached adult stage on the 19th day at salinity 20 ppt and on the 18th day at salinity 45 ppt [14]. Artemia reached adult stage on the 13th day with a body length of $11.86 \pm 0.09 \mathrm{~mm}$ when cultured in natural sea water [12]. Another study observed that Artemia living in natural environment was usually smaller than laboratory reared [15]. Most of the report says that the adult Artemia size was $10 \mathrm{~mm}$. However, Artemia reached $12 \mathrm{~mm}$ when it was reared in sea water followed by brackish water $(9 \mathrm{~mm})$ and freshwater (4 mm) [16].

The differences in hatching efficiency and hatching percentage of cysts are noticeable where more nauplii hatched out from the decapsulated cysts than the untreated cysts since the nauplii had to spend less energy to hatch from the cysts. The decapsulated cysts contain much higher energy content, since they do not have to expend energy in breaking out of shell [17]. If the decapsulated cysts are incubated for hatching as instar I nauplii, the hatchability is also improved, again because no shell breakout is required. However, the number of hatched nauplii determining the hatching efficiency and hatching percentage are sensitive to environmental factors and varying condition prior to and at cyst harvesting, cyst processing and storage $[18,19]$.

A study observed 17 populations where the mean diameter for chorionic cysts ranged from $221.0 \mu \mathrm{m}$ to $284.9 \mu \mathrm{m}$, and the values for decapsulated cysts ranged from $208.2 \mu \mathrm{m}$ to $258.8 \mu \mathrm{m}$, with the chorionic thickness ranged from $4.7 \mu \mathrm{m}$ to $13.3 \mu \mathrm{m}$ [20]. The mean diameter for chorionic cysts ranged from 247.63 $\pm 11.47 \mu \mathrm{m}$ to $259.34 \pm 11.36 \mu \mathrm{m}$; and the values for decapsulated cysts were $231.29 \pm 10.43 \mu \mathrm{m}$ to $251.6 \pm$ $11.24 \mu \mathrm{m}$, with the chorionic thickness ranged from $1.31 \mu \mathrm{m}$ to $9.37 \mu \mathrm{m}$ were found [21]. A study found the mean diameter for untreated cysts ranged from $262.7 \mu \mathrm{m}$ to $286.6 \mu \mathrm{m}$, decapsulated cysts ranged from $258.6 \mu \mathrm{m}$ to $274.4 \mu \mathrm{m}$, with the chorionic thickness ranged from $1.2 \mu \mathrm{m}$ to $9.3 \mu \mathrm{m}$ [22]. In the other study of the same population, the mean diameter of untreated and decapsulated cysts ranged from 249.8 $\mu \mathrm{m}$ to $280.7 \mu \mathrm{m}$ and $218.4 \mu \mathrm{m}$ to $259.8 \mu \mathrm{m}$, respectively. The chorionic thickness ranged from 2.7 $\mu \mathrm{m}$ to $15.6 \mu \mathrm{m}$. The variation between the mean diameter of untreated and decapsulated cysts, as well as, in chorionic thickness may be due to the cause of seasonal fluctuation in physico-chemical parameters and food availability [23]. These differences may be found in a site at different periods of time [21].

The present study on determining survival rate indicates that under laboratory condition a salinity of 35 ppt can greatly influence the survival of Artemia franciscana. 


\section{Conclusion}

At present, Bangladesh is showing better performance in aquaculture and day by day the land occupied by aqua farming is increasing with the increasing of protein demand. Since most fish and shrimps rely on live diets in the early larval stages, there is always a need for nutritious diets. Among those live diets, Artemia has become the most reliable and absolutely necessary food items. Study revealed that the modified salt beds of Bangladesh can successfully be used for culturing Artemia during winter months [6]. But the question remains unanswered whether the culture of Artemia only during winter months will meet the requirement for live diets or not? Apparently, the aquaculturists must focus on indoor hatching process of Artemia. Furthermore, the culture of Artemia is easy and requires fewer materials. The aquaculturists can easily feed their fish larvae with newly hatched nauplii, decapsulated cysts, dry cysts in powdered forms and also adults, according to the nutritional requirements.

\section{References}

[1] Lim, L. C., Dhert, P., and Sorgeloos, P. 2003. "Recent Developments in the Application of Live Feeds in the Freshwater Ornamental Fish Culture.” Aquaculture 227 (1): 319-331.

[2] Vanhaecke, P., Tackaert, W., and Sorgeloos, P. 1987. The Biogeography of Artemia: an Updated Review. In: Sorgeloos, Artemia research and its Applications. Vol. 1. Belgium: Universa Press, 129-155.

[3] Mahmood, N. 1990. Preliminary Study on the Culture of Artemia in the Coastal Salt Pans of Bangladesh. Final report. Inst. Mar. Sci. Univ. Chittagong, Bangladesh.

[4] Ahmed, S. U., and Awal, S. 1991. Integrated Production of Artemia with Salt from the Solar Salt Works of Bangladesh. Univ. J. Zool. Vol. 10-11. Bangladesh: Deptt. Zool. Univ. Rajshahi.

[5] Mahmood, N., BelalHaider, S. M., and Quaderi Saikat, S. 1993. "Successful Inoculation of Artemia and Production of Cysts in the Coastal Saltpans of Bangladesh II." Pakistan Journal of Marine Sciences 2 (1): 23-31.

[6] Ahmed, S. U., Rahman, M. A., Islam, M. N., Kamal, M., and Awal, S. 2000. "Study on the Impact of Fertilization on the Production of Artemia (Cyst and Biomass) and Salt in an Integrated System from the Solar Salt Works of
Bangladesh.” Pakistan Journal of Biological Sciences 3 (9): 1420-1423.

[7] Sorgeloos, P., and Kulasekarapandian, S. 1984. "Production and Use of Artemia in Aquaculture." CMFRI Special Publication 15: 1-73.

[8] Vanhaecke, P., and Sorgeloos, P. 1980. International Study on ArtemialV, the Biometrics of Artemia Strains from Different Geographical Origin. The Brine Shrimp Artemia, 3. Belgium: Universal Press, 393-405.

[9] Treece, G. D. 2000. "Artemia Production for Marine Larval Fish Culture.” Stoneville, Mississippi: Southern Regional Aquaculture Center (SRAC) 702: 1-8.

[10] Sato, N. L. 1967. "Enzymatic Contribution to the Encystment of Artemia salina.” Sci. Rep. Tohoku Univ. 33: 319-327.

[11] Sorgeloos, P., and Van, Stappen, G. 2014. "Impact of Brine Acidification on Hatchability, Survival and Reproduction of Artemia parthenogenetica and Artemia franciscana in Salt Ponds, Bohai Bay, China.” Chinese Journal of Oceanology and Limnology 32 (1): 81-87.

[12] Kuruppu, M. M., and Ekaratne, S. U. K., 1995. "Life History of the Brine Shrimp Artemia parthenogenetica Sri Lanka (Crustacea: Branchiopoda: Anostraca: Artemiidae).” J. South Asian Nat. Hist. 1: 203-212.

[13] Kulasekarapandian, S., and Ravichandran, P. 2003. “Artemia Cyst Production at Kelambakkam near Chennai.” J. Mar. Biol. Ass. India 45 (2): 166-177.

[14] Soniraj, N. 2004. "Effect of Salinity on the Life Span and Reproductive Characteristics of Brine Shrimps in the Salt Pans at Tuticorin.” J. Mar. Biol. Ass. India 46 (2): 133-140.

[15] Amat, F. 1980. Differentiation in Artemia strains from Spain. In: Persoone, G., Sorgeloos, P., Roels, O., Jaspers, E.eds. The Brine Shrimp Artemia. Vol. 1. Belgium: Universa Press, 19-39.

[16] Soundarapandian, P., and Saravanakumar, G. 2009. "Effect of Different Salinities on the Survival and Growth of Artemia spp." Current Research Journal of Biological Sciences 1 (2): 20-22.

[17] Vanhaecke, P., and Sorgeloos, P. 1983. "International Study on Artemia: XIX. Hatching Data for Ten Commercial Sources of Brine Shrimp Cysts and Re-evaluation of the "Hatching Efficiency" Concept." Aquaculture 30 (1): 43-52.

[18] Sorgeloos, P., Baeza-Mesa, M., Benijts, F., and Persoone, P. 1976. Current Research on the Culturing of the Brine Shrimp Artemia salina L. at the State University of Ghent, Belgium. In: Persoone, G. and Jaspers, E. (Eds.), Proc. 10th European Symposium on Marine Biology. Vol. 1. Belgium: Universa press, 473-495.

[19] Vanhaecke, P., and Sorgeloos, P. 1982. "International Study on Artemia. XVIII. The Hatching Rate of Artemia 
Cysts-a Comparative Study.” Aquacultural engineer 1 (4): 263-273.

[20] Naceur, H. B., Jenhani, A. B. R., and Romdhane, M. S. 2012. "Biometrical Study of Artemia spp. (Anostraca: Artemiidae) Cysts Harvested from Different Salt Lakes in Tunisia.” North-Western Journal of Zoology 8 (2): 308-314.

[21] Asem, A., Rastegar-Pouyani, N., and Agh, N. 2007. "Biometrical Study of Artemia urmiana (Anostraca: Artemiidae) Cysts Harvested from Lake Urmia (West Azerbaijan, Iran).” Turkish Journal of Zoology 31 (2):
171-180.

[22] Abatzopoulos, T. J., Baxevanis, A. D., Triantaphyllidis, G. V., Criel, G., Pador, E. L., Van Stappen, G., and Sorgeloos, P. 2006a. "Quality Evaluation of Artemia urmiana Gunther (Urmia Lake, Iran) with Special Emphasis on its Particular Cyst Characteristics (International study on Artemia LXIX).” Aquaculture 254 (1): 442-454.

[23] Abatzopoulos, T. J., Agh, N., Van Stappen, G., Razavi Rouhani, S. M., and Sorgeloos, P. 2006b. “Artemia Sites in Iran.” J. Mar. Biol. Ass. UK. 86: 299-307. 